Article

\title{
Varieties of Buddhist Healing in Multiethnic Philadelphia ${ }^{\dagger}$
}

\section{Pierce Salguero}

Division of Humanities, The Abington College of Penn State University, 1600 Woodland Rd., Abington, PA 19001, USA; salguero@psu.edu

+ Portions of this article have appeared in nascent form on the Jivaka Project website, http:/ /www.jivaka.net (all links up to date as of 4 January 2019). I wish to thank my research students and assistants, as well as the project's advisory board, all of whom are listed on the website's credits page. I also wish to thank Scott Mitchell, Michael Stanley-Baker, and all the colleagues who have commented on previous oral and written versions of this paper (most memorably at the 2016 AAR annual meeting and the 2018 gathering of the Philadelphia Area Buddhist Studies Working Group).

Received: 28 November 2018; Accepted: 10 January 2019; Published: 13 January 2019

\begin{abstract}
While an increasing amount of attention has been paid in the last decade to mindfulness meditation, the broader impact of Buddhism on healthcare in the United States, or any industrialized Western countries, is still much in need of scholarly investigation. The current article presents preliminary results from an ethnographic study exploring the impact of a wide range of Buddhist institutions, practices, and cultural orientations on the healthcare landscape of the Philadelphia metropolitan area. By particularly focusing on segments of the population that are non-white and that have limited English language skills, one of the main goals of this project is to bring more diverse voices into the contemporary conversation about Buddhism and wellbeing in America. Moreover, as it extends far beyond the topic of meditation, this study also is intended to highlight a wider range of practices and orientations toward health and healing that are current in contemporary American Buddhism. Finally, this paper also forwards the argument that the study of these activities should be grounded in an appreciation of how individual Buddhist institutions are situated within specific local contexts, and reflect unique configurations of local factors.
\end{abstract}

Keywords: Buddhism; medicine; health; immigration; Asian American

The impact of Buddhism on healthcare in the United States or any of the industrialized Western countries is still much in need of scholarly investigation. To date, only one piece of this overall puzzle has been amply documented in English-language scholarship. In America, mindfulness meditation has recently gone from being a relatively marginal activity to an accepted part of mainstream healthcare. This fact has led scholars from across the academy (not to mention practitioners, scientists, and the popular media) to write voluminously on the subject. ${ }^{1}$ At the same time that scholarship on mindfulness is welcome and important, the rising star of this particular practice has tended to outshine all other connections between Buddhism and healing. More specifically, as mindfulness is the Buddhist-inspired method that is most popular with Caucasian practitioners, it has tended to overwhelm the literature on the experience of lived Buddhism among Asian-Americans and other people of color. ${ }^{2}$

1 See, for example, (Wilson 2014; Purser et al. 2016).

2 See critique in (Hsu 2016). See also related critiques of the whiteness of American Buddhist studies in (Quli 2009; Hickey 2010; Cheah 2011). 
Aside from the topic of mindfulness, only a small number of articles have explored a wider range of contemporary Buddhist healing and health-seeking practices, and these have tended to focus narrowly on one particular temple or group of practitioners. ${ }^{3}$ To my knowledge, there have been no large-scale studies of the role of North American Buddhism in shaping health-seeking attitudes and behaviors in a wider swathe of geography or population. The current article begins to remedy this lacuna by presenting preliminary results from an ethnographic study exploring the impact of a wide range of Buddhist institutions, practices, and cultural orientations on the healthcare landscape of metropolitan Philadelphia. By particularly focusing on segments of the population that are non-white and that have limited English language skills, one of the main goals of this project is to bring more diverse voices into the contemporary conversation about Buddhism and wellbeing in America. Moreover, as it extends far beyond the topic of meditation, this study also is intended to highlight the wider range of practices and orientations toward health and healing that are current in contemporary American Buddhism.

Finally, this paper also argues that the study of these activities necessitates an appreciation of how individual Buddhist institutions are situated within specific local contexts. Throughout the paper, I use terms such as "Buddhist healing" and "Buddhist health-seeking activities." The former is an operative phrase among some (though by no means all) of Philadelphia's Buddhist communities, while the latter never is. These are analytical, scholarly categories that I am using in order to discuss and compare what is essentially a diffuse range of discrete (and sometimes mutually unintelligible) practices. The point is precisely not to establish a unified entity called "Buddhist healing," but rather to draw attention to the diversity of specific ways that particular communities in Philadelphia draw upon Buddhist ideas, practices, institutions, and other resources in their pursuit of health.

\section{Philadelphia's Multiethnic Buddhist Landscape}

With over 1.5 million residents in the city proper, and nearly 6.1 million in the greater metropolitan area, Philadelphia is today the eighth largest urban center in the US. ${ }^{4}$ A major port city and economic hub located at the geographic center of the "Northeastern megalopolis" that stretches between Boston and Washington DC, Philadelphia is an important a point of arrival and settlement for immigrants from around the world. While the size of its Asian immigrant community is not as large as New York or Los Angeles, the US Census Bureau estimated in 2016 that $7.4 \%$ of the city's residents were of Asian descent, which is above the national average of $5.2 \%$. With significant percentages of Asian residents in several surrounding counties as well, Greater Philadelphia has a large and diverse enough Asian population to support a wide range of Buddhist temples associated with a number of different denominations and ethnic groups.

Asian immigration in Philadelphia has historically been shaped by national and international politics. ${ }^{5}$ The city's Chinatown is said to have begun in 1871 with the establishment of a Chinese laundry at 913 Arch Street, during the first major wave of Chinese immigration to the East Coast. Largely due to the activism of the local Quaker community, the city became a major hub for resettling Japanese Americans freed from West Coast internment camps in the 1940s. Refugees from Soviet Kalmykia and Chinese-occupied Tibet established a Buddhist temple in the area in the 1960s. While the city's overall immigrant population remained low throughout most of the twentieth century, the number of Asian Philadelphians began rising after the 1965 Hart-Celler Act lifted national quotas for Asian immigration. Arrivals from Korea, China, Vietnam, and Cambodia in particular increased as a consequence of conflict and wars in Asia. The percentage of foreign-born people who identified as

(Wu 2002; Numrich 2005).

The source for the statistics in this paragraph is the 2012-2016 American Community Survey 5-Year Estimates, https://www.census.gov/programs-surveys/acs/.

5 For histories of Asian American immigration, see (Takaki 1989; Chan 1991; Cheah 2011). Indian and Pakistani groups are also extremely populous in Philadelphia, but since they tend not to be Buddhist, they will not be discussed here. 
Asians more than tripled between 1970 and 1980, and nearly doubled again between 1980 and $1990 .^{6}$ In the 1990s and 2000s the economic revitalization of the city began attracting even larger waves of newcomers. ${ }^{7}$ Philadelphia's current status as a "sanctuary city" (meaning it does not fully enforce US federal immigration policy) makes it likely to continue to attract large numbers of both legal and undocumented immigrants from Asia and around the world in the immediate future.

As a direct consequence of the marked increase in Asian immigration, Philadelphia currently has a number of relatively new Buddhist temples that cater primarily to communities comprised of firstand second-generation Americans. I have over the past few years organized a multi-sited ethnographic project that has surveyed and mapped Greater Philadelphia's Buddhist temples, meditation centers, and other self-described Buddhist organizations. ${ }^{8}$ To date, small teams of undergraduate students and I have catalogued and conducted interviews at 44 sites as part of this project.

Thirty-six of the 44 sites we have visited were founded primarily to serve Asian immigrant populations. Ten of those are predominantly of Chinese ethnic affiliation, nine are Vietnamese, four Korean, four Cambodian, three Taiwanese, two Lao, and one each for Burmese, Japanese, Mongol/Kalmyk, and Thai. ${ }^{9}$ Twenty-two are affiliated with various forms of East Asian Mahāyāna, eight with Theravāda, and three predominantly with Vajrayāna or Esoteric Buddhism. In addition, there are three temples that represent modern or non-traditional denominations (Buddhist Churches of America, Guan Yin Citta Dharma Door, and Won Buddhism). ${ }^{10}$

Aside from those 36 organizations that primarily cater to Asian and Asian American communities, our study also includes eight meditation centers within Greater Philadelphia that attract primarily non-Asian practitioners. Some of these institutions are local chapters of international Buddhist organizations-such as New Kadampa Tradition (NKT), Shambhala Buddhism, and Soka Gakkai International (SGI). ${ }^{11}$ Others are independent entities or are loosely connected with various national or international Buddhist networks. The attendees of these meditation centers are predominantly Caucasian, with the exception of the SGI chapter in Center City (whose congregation is majority non-white) and the People of Color Sangha that meets at Springboard Studio in the suburbs (which is completely non-white).

Most temples are located in neighborhoods with comparatively large populations of their dominant demographic. Chinese temples, for example, tend to be clustered in neighborhoods with higher than average percentages of residents who are ethnically or culturally Chinese. ${ }^{12}$ Meanwhile,

(Amsterdam and Vitiello 2013).

(Pew Research Center 2018).

See interactive searchable map on the project website. Our survey has been limited to including only organizations that maintain permanent physical locations that we could find by conducting various types of online searches. However incomplete, these results are nevertheless sufficient to give the reader a sense of the ethnic and linguistic diversity of the Buddhist landscape in the city. All of the figures cited in this paper should be considered to be accurate at the time of this writing, but the exact number of Buddhist institutions included on our map is constantly in flux as we become aware of new ones opening or existing ones closing down. Also note that there are some other maps of Philadelphia's Buddhist temples available online, principally the one at http://pluralism.org/landscape/philadelphia/, which are extremely out of date or incomplete and thus inaccurately reflect the current shape of Philadelphia Buddhism.

9 In this article, as in the project itself, I do not take into account whether or not immigrants are legally documented. Thus, when I speak of a "Chinese" temple, I am describing an institution that serves a population who self-identify as culturally and/or ethnically Chinese, and am not referring to the nationality or citizenship of the participants. Likewise, I do not intend the term "Chinese" to describe the origins of the institution. Many of Philadelphia's temples are indeed branches of temple organizations headquartered in Asia, although there are even more that were founded as separate legal entities in the US, either in Philadelphia or elsewhere.

10 This is not the place to enter into the debate over whether Won Buddhism qualifies as a form of Buddhism, or should instead be seen as a New Religious Movement (see Pye 2002; Baker 2012). For present purposes, if an organization operates in the Philadelphia area and self-describes as a form of Buddhism, then it is included in our project.

11 This is also not the forum to discuss the scholarly or political controversies surrounding several of the international organizations on this list. Note that students are not encouraged to join any of the organizations or to practice their teachings as part of their fieldwork.

12 However, this is not always the case. For example, a large and well-financed Thai temple thrives in suburban Ben Salem, an area without significant Thai population. See below for the case of a Korean temple. Sometimes, such anomalies are the result of the historical relocation of a population from one neighborhood to another, while in other cases is has to do with 
meditation centers are typically located in relatively affluent neighborhoods, often operating out of storefront properties in high-traffic areas of Center City or the suburbs. ${ }^{13}$

\section{Philadelphia's Buddhist Healing Repertoire}

Between 2015 and 2018, we conducted multiple interviews at all 44 locations, speaking with monastics, lay leaders, spokespeople, representatives, and occasionally ordinary members about Buddhism and health. ${ }^{14}$ In almost all cases, when asked if there were any ways that the practice of Buddhism influenced one's health, interviewees responded in the affirmative. ${ }^{15}$ (Only one respondent in our survey, a Korean Mahāyāna monk, rejected altogether the notion that Buddhist practice could have any concrete benefit for one's health.) In many cases, our interlocutors were keen to distinguish that Buddhist practice affects mental, social, and/or spiritual health, rather than directly healing physical diseases. Nevertheless, these same individuals often elaborated that, because mind and body are inter-connected, physical healing often is achieved. ${ }^{16}$ The overwhelming majority of the people we interviewed thus agreed that Buddhist practices have beneficial effects on both the physical and mental dimensions of health, wellbeing, or longevity.

While there was thus general agreement that Buddhism has positive impacts on health in the broad sense, the specific practices respondents had in mind when they responded to our questions differed, often dramatically. The full range of healing and health-seeking activities uncovered in our survey cannot be detailed here. ${ }^{17}$ However, in summary, the reported activities we recorded ranged across the following six dimensions:

\subsection{Meditation}

One type of healing activity that is common across Philadelphia-as it is across the modern Buddhist world-is contemplative practice that can loosely be called meditation. ${ }^{18}$ Silent seated

locating a temple equidistantly between more than one pocket of supporters or with the availability of a larger tract of land at some distance from the community.

13 Our research does not reveal a significant pattern concerning other aspects of demography, such as age. There are some temples in the Philadelphia area that are attended by a small congregation of mostly elderly people, while others are bustling with families and young children. Some temples provide childcare during weekly services in the form of "Sunday school" classes, and some organize other cultural and learning programs throughout the week, such as dance or language classes. Such activities seem not to depend on the particular sectarian or cultural affiliation of the institution. However, it should be noted that meditation centers cater strictly to adult practitioners, and never offer programming for young children. Finally, our research revealed some unsurprising trends with regard to the sex of participants in Buddhist organizations. While temples and meditation centers alike attracted an essentially even split of male and female participants, with perhaps a slight preference for women, leadership positions within the organizations across the Philadelphia area followed predictable sectarian and cultural norms. In Theravāda temples in the Thai, Cambodian, Lao, and Burmese traditions, monastic orders are exclusively male, although women typically serve as the most visible lay leaders and participants. Among the Mahāyāna temples, on the other hand, several were run by female nuns or priests at the time of our survey. Among the meditation centers, we found that a majority were being led by female teachers. We did not identify a significant diference between the health activities of temples based on the leaders' gender.

14 Observations in this paper, including the case studies, are drawn from data collected over multiple visits to each location between Fall semester 2015 and Fall semester 2018. For more details about the responses, see a collection of excerpts from these interviews in chapter 35 of (Salguero forthcoming). Although our project was determined to be exempt from IRB oversight, all interviewees gave their informed consent for inclusion in either English or their native language before they participated in the study. Our consent forms and interview scripts are publicly posted on the Pedagogy page of the project website.

15 In these unstructured interviews, we attempted to phrase our questions as broadly as possible so as to minimize predetermining the answers we would receive. We also attempted as much as possible to frame questions in culturally appropriate terms. Frequently, we were assisted in this regard by "cultural liaisons"—-student researchers who had the appropriate language skills and understood the relevant social norms. Nevertheless, in a study such as this one, the divergences in how people from different cultures understand health, healing, medicine, and other key terms in our line of questioning is a persistent issue. I will bracket off further discussion of that particular topic for a future publication.

16 Language that distinguishes mind and body as two separate, but interrelated phenomena is routine in Buddhism. While they saw them as interrelated, in no cases did respondents argue that mind and body were the same thing.

17 For more details on individual locations, see entries in the project's online "Location Finder."

18 For a study of the surprisingly modern history of meditation as a lay practice, see (Braun 2013). For a variety of contemporary perspectives, see (Wilson 2014; Purser et al. 2016; McMahan and Braun 2017). 
meditation is the main focus of the meditation centers, where spokespeople readily connected the practice with wellness, and particularly highlighted its positive effects on mental health. The vast majority of temples, on the other hand, neither teach meditation publicly nor include it in their regularly scheduled weekly services. Nevertheless, when questioned by our research team, representatives of these institutions were nearly universal in their readiness to mention meditation as an important practice for lowering stress and creating better conditions for harmony between mind and body. Interviewees at Theravāda temples placed particularly heavy emphasis on meditation.

The most prominent form of meditation mentioned by respondents-whether representatives of temples or meditation centers-was mindfulness of the breath. Although called by different names depending on the tradition or language spoken, this basic Buddhist technique was widely characterized by spokespeople from virtually all ethnic and sectarian groups as being good for one's wellbeing. Calming stress and settling the mind through meditation was reported to lead to increased psychological and physical healing, to mitigate the suffering of illness, and to transform one's daily habits in health-promoting ways.

Aside from mindfulness, some respondents specifically related other contemplative techniques to physical healing. These included a meditation taught at the Thai temple, Wat Mongkolthepmunee, in which the meditator visualizes a crystal ball within different parts of the body. ${ }^{19}$ Several Thai interviewees mentioned the power of this visualized crystal to purify and heal the body from within. ${ }^{20}$ A meditation focusing on the center of qi-energy in the body (Ch. dantian; $\mathrm{Kr}$. danjeon), was mentioned at both the Korean Won Buddhist Temple and the Chinese Rulai Si. Respondents at both temples described the regulatory effects of this meditation on the body's organs and physiological functions. In addition, various forms of movement-based contemplative practice, such as qigong, taijiquan, and yoga are regularly taught at several meditation centers. The Won Buddhist Temple teaches its own brand of "moving meditation," which is similar in many ways to qigong, and also is explained through the concept of $q i$.

Finally, there are a few centers in Philadelphia that teach Vajrayāna healing visualizations. The Kadampa Meditation Center teaches a form of tonglen where the practitioner is taught to visualize breathing out black smoke to release illness, negative energy, and suffering from the body. The Chenrezig Tibetan Buddhist Center teaches visualization of the goddess Tārā in the form of the mantric syllable TĀṂ. Visualized above the practitioner's head, the syllable emits white light, symbolizing the protective and healing energies of the goddess, which descend along the chakras to align and purify the body.

\subsection{Healing Rituals}

Even more common than meditation at Philadelphia's Buddhist institutions is healing with ritual. Virtually all Buddhist traditions worldwide have well-developed repertoires of healing rites, and many of these are practiced in the area. In Mahāyāna Buddhist contexts, which represent half of the institutions in our study, healing rituals typically involve prayer and offerings to call upon deities to intercede in preserving supplicants' health and overcoming their illnesses. ${ }^{21}$ The most prevalent Mahāyāna healing deity in Philadelphia is Avalokiteśvara (Figure 1), the savior-bodhisattva associated with compassion. ${ }^{22}$ She—or, in Vajrayāna centers, "he"—is known by different names, including Guanyin (Ch.), Quan Âm (Vtn.), Kwan Um (Kr.), and Chenrezig (Tib.). The second most common is

19 For more about this temple, see (Cadge 2004). This temple is connected with Wat Paknam Bhasicharoen in Thailand, and the crystal ball meditation originating at that temple has been widely popularized by the Dhammakaya order in Thailand.

20 See an excerpt from one of these interviews in chapter 35 of (Salguero forthcoming).

21 For an overview of healing rites in various historical and contemporary Buddhist traditions, see (Salguero 2017; Salguero forthcoming).

22 On this deity, see sources cited in the previous note and also (Yü 2001; Wilson 2008). Note that while Avalokiteśvara is nominally a Mahāyāna deity, he/she also occasionally appears in non-Mahāyāna temples. Such is the case in Figure 1, which is from the basement level of the formal ceremonial hall of the Thai Theravāda temple. 
the "Medicine Buddha," Bhaiṣajyaguru, known as Yaoshifo, Dược Sư, Yaksabul, or Menla (Figure 2). ${ }^{23}$ In most Mahāyāna temples, rituals explicitly calling upon one or both of these deities for healing or protection from illness are incorporated into the standard devotional services that are held on a weekly basis. Some temples additionally organize annual or periodic events that bring together the community for special worship.

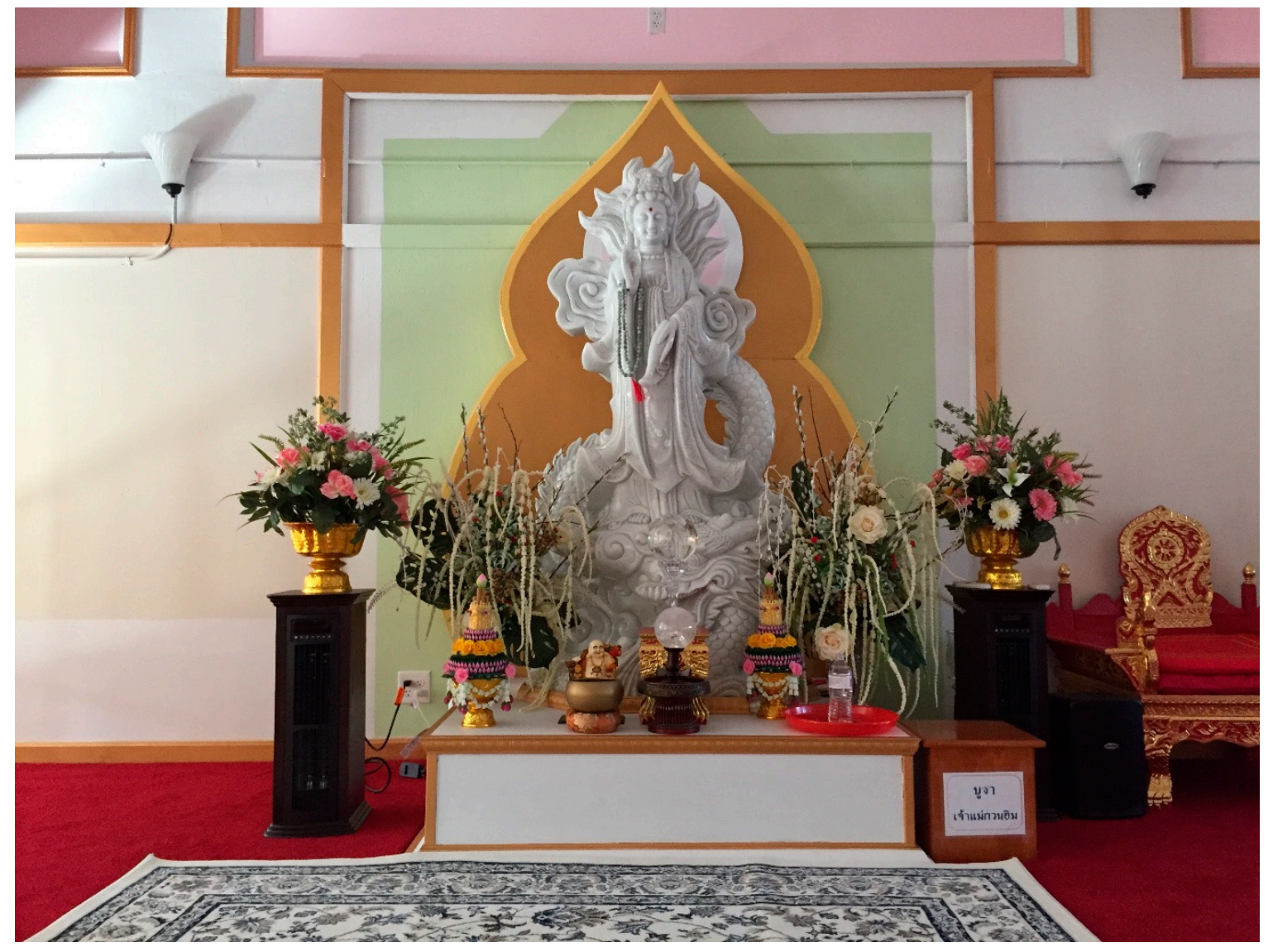

Figure 1. Avalokiteśvara (Th. Kuan Im), the savior-bodhisattva associated with compassion, at Wat Mongkoltepmunee (Bensalem, PA). Source: www.jivaka.net. All photos in this article were taken by project participants, and have been released to the public under the project's Creative Commons BY-NC-SA license.

One of the most common forms of healing ritual in Mahāyāna Buddhist communities is the chanting of sūtras (i.e., Buddhist scriptures) or mantras (i.e., shorter incantations in more condensed formats). While specific sūtras can be chanted for a variety of different purposes, certain titles appeared again and again in the context of health. These most notably include the Medicine Buddha Sütra, the Diamond Sütra, and the Heart Sütra-all mainstays of East Asian Buddhist healing practice. The most common mantras to appear in our survey were the "Great Compassion Dhāran̄i," a popular incantation associated with Avalokiteśvara, as well as the "Medicine Buddha Mantra." ${ }^{24}$ It is worth emphasizing that the chanting of sūtras and mantras is not limited to temples serving primarily Asian-American communities, but can also be found in some primarily non-Asian meditation centers as well (for example, at Soji Zen Center and SGI). ${ }^{25}$

23 See (Salguero 2017; Salguero forthcoming; Birnbaum 1989).

24 The Medicine Buddha Sūtra and the "Great Compassion Dhāran̄̄̄" are both translated in (Salguero 2017, pp. 235-85).

25 See excerpt of an interview with a SGI member in chapter 35 of (Salguero forthcoming). 


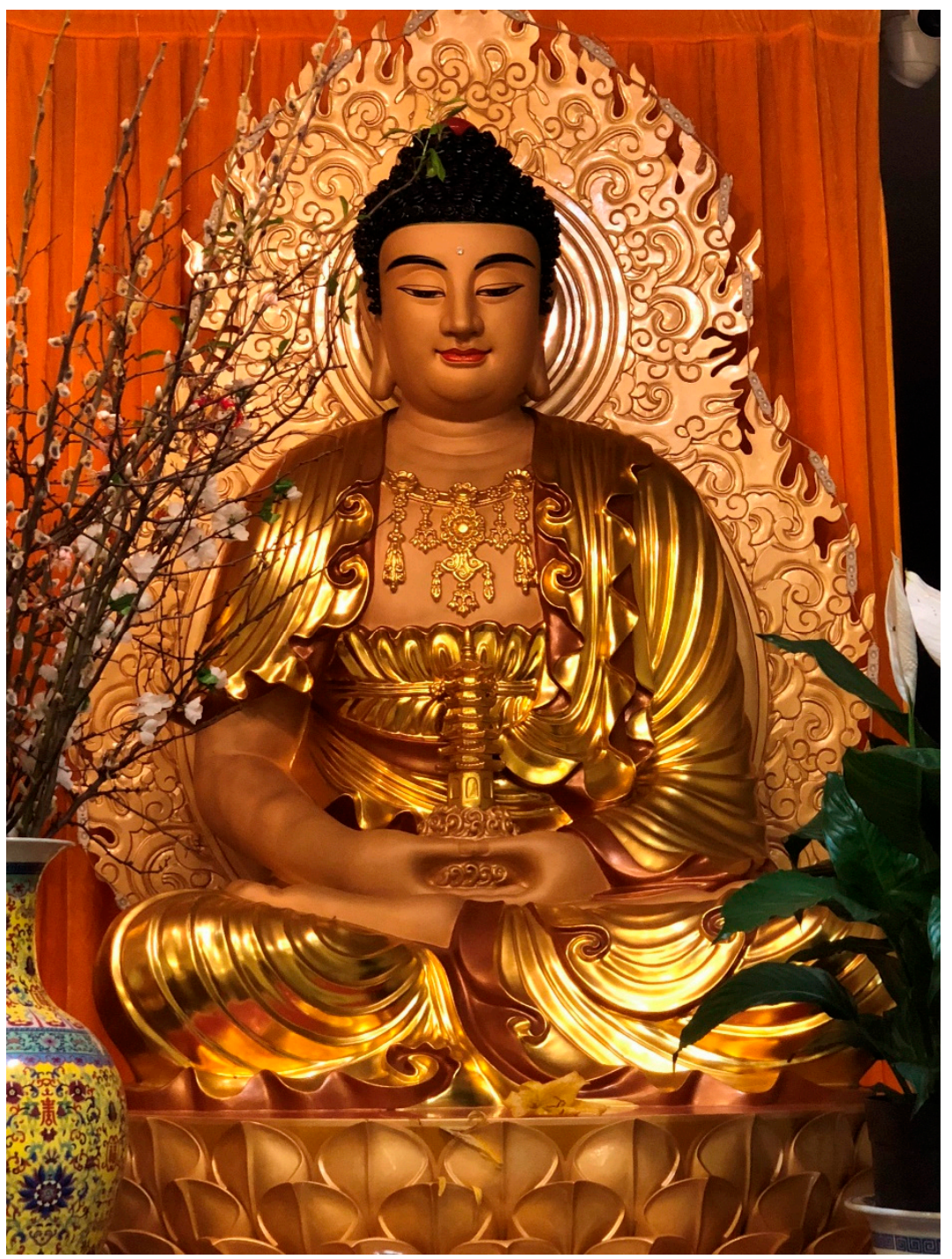

Figure 2. The "Medicine Buddha," Bhaișajyaguru, at Fou Shou Si (Chinatown, Philadelphia). Source: www.jivaka.net.

Aside from public rituals, private healing rites may also be commissioned for purposes of purification and protection. Such events can be arranged by individuals or families, and can be aimed at overcoming personal bouts of illness or other health-related misfortunes. In Mahāyāna temples, private healing rituals often consist of the same sorts of actions as might be done in a public ceremony - prayer, giving of offerings, and chanting - though now personalized for the family or individual patron. In some Theravāda and Vajrayāna temples, which tend not to hold public rituals specifically focused on healing, personal healing rites involve methods that are not normally conducted in public-such as spirit channeling, exorcism, or other esoteric activities. The officiants of such rites are typically monastics, although in some communities lay ritual specialists are also utilized. ${ }^{26}$

26 For example, in the Cambodian community, lay Buddhist ritualists known as achar conduct many of the personalized healing rituals, including communicating with and managing ghosts and spirits. An excerpt of an interview with one informant is reproduced in chapter 35 of (Salguero forthcoming). 


\subsection{Food and Health}

Food invariably plays an important role in Buddhist rituals and other events. Whether offered on an altar, donated to monastics, or shared among attendees, food is a vital part of the economy of gift-giving at the temple and is central to the practice of earning karmic merit in most Buddhist traditions. Karmic merit, in turn, is widely perceived as playing a role in keeping one healthy and safe. Social interactions before and after public ceremonies thus often center around the kitchen, and often involve the preparation, sharing, and eating of food. Many Asian medical and folk traditions hold that specific foods or herbs used in cooking provide particular health benefits, and these linkages are frequent topics of conversation among those who prepare food in temple kitchens.

All East Asian Mahāyāna Buddhist respondents who mentioned vegetarianism advocated it first and foremost on ethical grounds; however, many additionally talked about how a vegetarian diet is healthier (citing reduced cholesterol and saturated fats, for example). In some instances, Buddhist temples have been locations where more extensive community education about nutrition, diet, and health has taken place. The most obvious example of this was the "Healthy Monk Project," a collaboration between the Lao community at Wat Phouthathammram and the Philadelphia College of Osteopathic Medicine, which began with a focus on improving the resident monks' nutrition. ${ }^{27}$ The Buddhist Tzu Chi Foundation Philadelphia Service Center (a local branch of a major Taiwanese Buddhist organization) also has periodically organized community educational events about nutrition at their Chinatown location. ${ }^{28}$

\subsection{Traditional Asian Medicines}

In addition to the patently Buddhist therapies mentioned above, temples and meditation centers are often sites for the practice of a range of Asian health traditions that are not uniquely associated with Buddhism. Qigong, taijiquan, yoga, and medicinal foods have already been mentioned above. In addition to these, acupuncture, herbal medicine, cupping, scraping, massage, and other therapies are also practiced at various Buddhist locations. ${ }^{29}$ Most exchanges of traditional Asian medicines occur in informal settings, perhaps before or after public ceremonies, and receive no official endorsement or support from organization leadership. However, some institutions explicitly promote certain practices or traditions. The building might include a dedicated space for treatments, for example, or the resident monk might grow medicinal herbs in a garden on the temple grounds (see below).

The Won Buddhist Temple is more heavily involved in traditional Asian medicine than any other Buddhist institution in the area through its educational branch, the Won Institute of Graduate Studies. This is a separate legal entity founded by the temple community in order to forward Won Buddhism's mission of education in traditional Asian medicine. Serving a primarily English-speaking non-Asian student body, the school is an accredited grantor of master's degrees in acupuncture and Buddhist studies, as well as certificates in Chinese herbal medicine. They also run clinics and special events where members of the public can receive treatments.

\subsection{Social Dimensions of Health}

Buddhist institutions also serve as community centers and have social spaces that serve as information hubs. Informal flows of information often focus on issues related to health, such as when members exchange via word-of-mouth recipes for medicinal teas, recommendations for certain online resources, or directions to a particular healthcare center. Community bulletin boards are another common feature of these spaces, and these sometimes feature advertisements for specific healthcare

27 (Scott 2015).

28 On this international Buddhist charity, see (O'Neill 2010; Yao 2012).

29 On the use of traditional medicine among congregants, see also (Numrich 2005), although see the critique of the "two Buddhisms" approach used in that essay both below and in (Hickey 2010). 
practitioners. Exchanges such as these can also be seen taking place at English-speaking meditation centers; however, they take on additional importance in immigrant communities, as the temple may be one of the few environments where information is gathered and disseminated in the members' native language. These spaces also provide connections with aspects of heritage and culture that help to reinforce the community's identity and a sense of belonging, which researchers have shown to contribute positively to psychological wellbeing among refugee and immigrant populations. ${ }^{30}$

The importance of these social dimensions is even further amplified for groups who have come to Philadelphia fleeing violence or political persecution. For example, when asked about Buddhism's role in healing, two Cambodian interviewees credited their neighborhood temple with helping to "heal" the traumas the community had experienced during the Cambodian Civil War (1968-1975) and during their subsequent dislocation to refugee camps and eventually to Philadelphia. ${ }^{31}$ Another site where the temple is credited with a role in overcoming communal trauma (although not in this case specifically characterized as "healing" by interviewees) is the Seabrook Buddhist Temple, a Buddhist Churches of America branch founded in 1945 in rural New Jersey, an hour east of the city. About 500 Japanese American families were relocated to this area after being released from WWII internment camps in order to work at the local Seabrook Farms food processing operation. ${ }^{32}$ During our interviews with some of the original members of the Japanese-American community, as well as their descendants, they reported that the temple was a valuable cultural center that provided the community with a place to come together socially, as well as a doctrinal framework through which to come to terms with the tumultuous events that they had experienced.

\subsection{Intersections with the Mainstream Healthcare System}

Finally, Buddhist organizations of all kinds intersect in a variety of ways with the mainstream healthcare system in the Philadelphia area. Buddhist temples and other institutions serving immigrant communities are often involved in helping newly arrived members to acquire medical insurance, Medicare, and Medicaid, as well as to connect with recommended hospitals or doctors. They may additionally organize transportation and translation services to accompany members who do not speak English to medical appointments.

In addition to such efforts on behalf of individual members, Buddhist organizations sometimes collaborate with mainstream healthcare institutions of various sorts to organize community projects. As already mentioned, temples might serve as locations for periodic health clinics or health fairs. These are usually organized by individual members of the community who work in the healthcare sector, who act as liaisons between the temple and the hospital, nursing school, or other participating healthcare institution. These events typically allow members of the community and neighborhood the opportunity to receive flu shots, diabetes screening, blood pressure check-ups, and other routine procedures.

Connections cultivated between Buddhist organizations and hospitals also include the work of Buddhist interfaith chaplains. We interviewed two chaplains, one Taiwanese and one Caucasian, who were affiliated with the Philadelphia Buddhist Association, a local meditation group. Both reported that their interfaith chaplaincy work was grounded in and informed by Buddhist practices, such as meditation, sūtra chanting, and mantras. ${ }^{33}$ In another, more ambitious type of collaboration with hospitals, the Won Institute of Graduate Studies briefly operated the Won Center for East West Medicine, an acupuncture clinic inside of the Hahnemann University Hospital in Center City Philadelphia. (The unit was unsuccessful and had been closed by the time we began interviewing.)

\footnotetext{
30 See, e.g., (Beiser and Hou 2017), which analyzed data from over 1400 migrants to Canada.

31 See excerpt from this interview in chapter 35 of (Salguero forthcoming). For context, see, e.g., (Ong 2003).

32 For context, see, e.g., (Williams 2019).

33 See an excerpt from one of these interviews in chapter 35 of (Salguero forthcoming).
} 
Aside from collaborations with mainstream medical institutions, there are several local Buddhist community service organizations that are dedicated to serving the healthcare needs of new immigrants and refugees. Though non-profits legally independent of any religious organization, these charities are typically headquartered within Buddhist institutions, are staffed by clerics or temple members, and explicitly expressed Buddhist values in their interviews with us. Two examples include the Won Community Services Center (operated out of the Won Buddhist Temple) and Tzu Chi's center in Chinatown. Both of these organizations have been active in serving the medical needs of recent immigrants in the area, among other kinds of charitable activities.

\section{Locally Contextualizing Buddhist Healing}

The previous section summarized the most common healing and health-seeking practices found across the spectrum of Buddhist institutions around Greater Philadelphia. As it has focused on outlining the overall repertoire of practices, however, the discussion thus far has been dealing mostly in generalities. The details of which kinds of activities are practiced, and how, in fact differ markedly from location to location.

While there are some general patterns that have already been mentioned above (such as Theravāda temples emphasizing meditation or Mahāyāna temples emphasizing healing deities), our research in Philadelphia suggests that generalizations based on macro-level attributes, such as culture, ethnicity, or sectarian affiliation are too blunt to be very useful. For example, the "two Buddhisms" taxonomy-which distinguishes "Asian," "ethnic," or "traditional" Buddhism on the one hand from "Western" or "convert" Buddhism on the other-is not only problematic from a theoretical standpoint, ${ }^{34}$ but it also conceals the diversity of Buddhist healing on the ground. The healing repertoires at any given Vietnamese temple are likely to be quite distinct from those at a Cambodian temple, for example, although recent immigrants may predominate at both. Moreover, whatever specific practice one might hold out as an example of an "Asian" approach (sūtra chanting, say) can readily be found within so-called "convert" institutions, and vice versa. ${ }^{35}$

A model that accounts for a wider range of ethnic or cultural affiliations than simply "Asian" vs. "Western" is somewhat more helpful, but still cannot adequately capture the diversity of Philadelphia's Buddhist landscape. Surely, there are certain healing repertoires that are commonly available to all temples of a particular heritage. All Chinese temples we have visited in Philadelphia, for example, have statues of the bodhisattva Guanyin which can be propitiated for health and wellbeing. Emphasizing this commonality, however, glosses over the stark differences in the Guanyin practices that are found among specific Chinese Buddhist communities. While they may share certain features, two culturally Chinese temples can differ as much from one another in terms of what healing practices they advocate than either does from a Lao Theravāda temple or a Caucasian Vajrayana meditation center. ${ }^{36}$ Consider, for example, the devotees at Guanyin Citta Dharma Door, who record their devotional chanting to Guanyin by filling in tally cards (zeng; Figure 3) that subsequently serve as a karmic currency of sorts. Collecting a certain number of completed cards enables members to bribe demons and ghosts, or to pay for good health outcomes. Contrast that with the socially engaged volunteer work done by members of Tzu Chi. Here, Guanyin's compassion is not something accumulated and stored for later transactions, but rather is enacted and embodied by individual devotees while working on specific projects for the benefit of the community. In both cases, the central point of reference is the same deity, Guanyin, and the shared cultural context for that deity is

34 Scholars have critiqued this particular model-as well as other attempts to classify American Buddhists based on race, ethnicity, and immigration status (Baumann 2006) — as being tainted with overt or covert racism. See the thoroughgoing critique in (Hickey 2010).

35 Observations made about the use of complementary/alternative medicine among the "two Buddhisms" in (Numrich 2005), for example, are not generalizable to Buddhist communities we interviewed in Philadelphia.

36 And thus, observations about the community described in ( $\mathrm{Wu} 2002$ ), for example, do not speak for all other Chinese Buddhists. 
broadly Chinese. However, the doctrinal interpretations, ritual protocols, material culture, and social interactions are completely different.

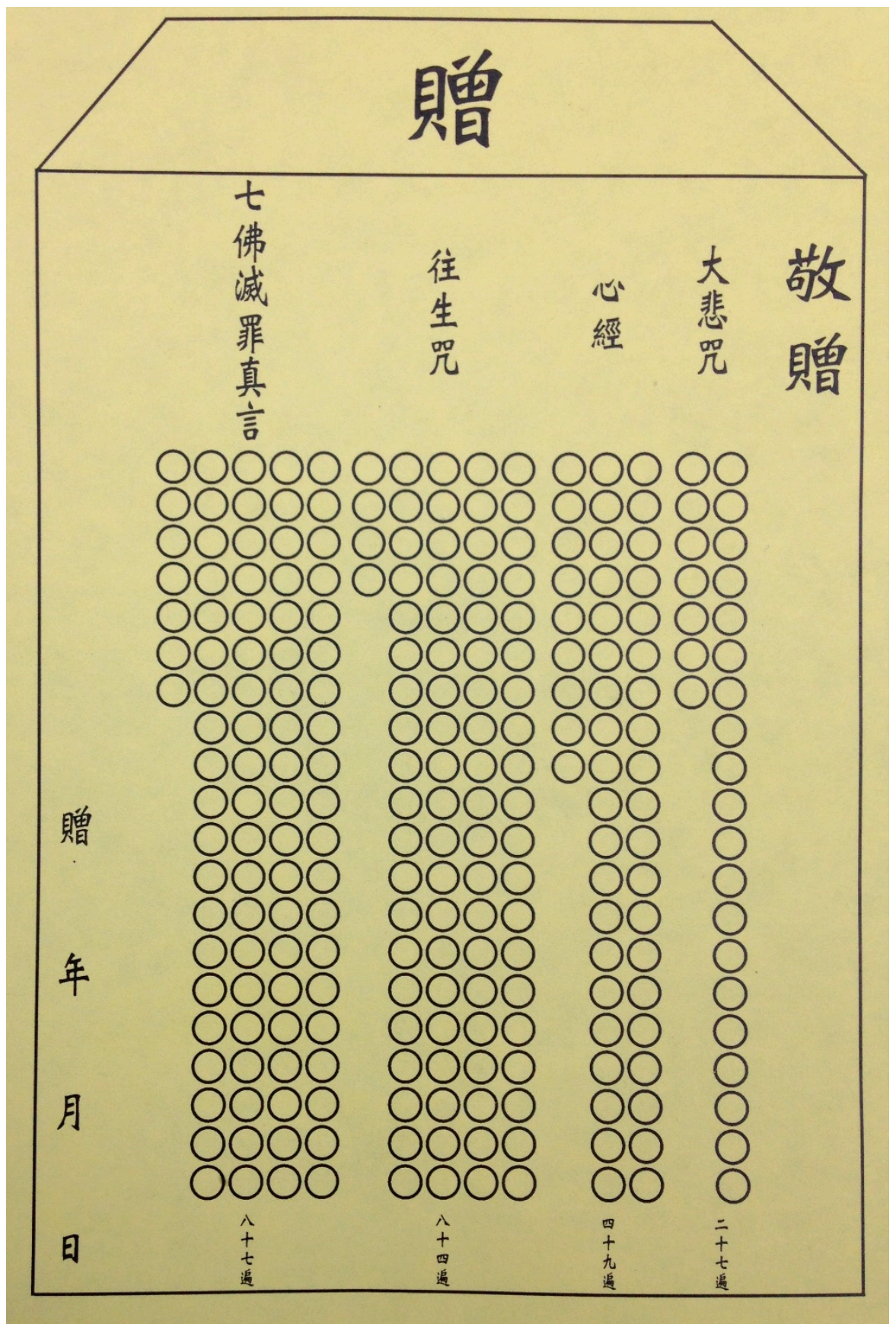

Figure 3. Chanting tally card (zeng) from Guanyin Citta Dharma Door (Chinatown, Philadelphia).

Source: www.jivaka.net.

If ethnicity and culture do not wholly account for the differences between institutions, Buddhist sectarian affiliation does not either. It is generally true that when temple spokespeople respond to our inquiries about health, they draw upon their own particular doctrinal context to explain Buddhist practices and their efficacy. Representatives of Theravāda institutions, it has already been noted, are likely to speak at length about the effects of meditation in terms of lowering mental volatility and increasing a sense of peace. They often speak of the power of Buddhist practice to improve one's karma, and lay stress on the need to live an ethical or moral life. On the other hand, 
Mahāyāna practitioners are likely to recognize those aspects as valid, but also to discuss the power of certain rituals, sūtras, or mantras, and the intervention of particular deities in health. Meanwhile, representatives of Vajrayāna institutions tend to recognize all of the above, but to also place emphasis on visualizations or other purification practices that specifically target health outcomes. Various modern or non-traditional forms of Buddhism (such as Won, SGI, NKT, and Shambhala) likewise each approach health from within their own doctrinal paradigms.

At the same time that these generalities pertain, however, sectarian affiliation is far from determinative. Each Buddhist tradition is rich enough and internally diverse enough that it affords members a wide variety of practices from which to draw. Additionally, specific members or groups of congregants often adopt practices or seek resources outside of the dominant doctrinal framework of their own temple or tradition (see example below). Moreover, a few of the locations in Philadelphia explicitly cater to more than one denomination, which means individual members may routinely be exposed to broader repertoires. For example, Pumen $\mathrm{Si}$, a Buddhist community shrine in Chinatown, has a main hall in which a conventional Mahāyāna altar is established with all of the usual accoutrements, while a separate, smaller room in the back houses iconography, furniture, and ritual implements associated with Taiwanese-style Esoteric Buddhism. These two spaces allow the center to serve the needs of different facets of the Chinese-speaking Buddhist community in the neighborhood, and to host different types of practitioners and teachers in the space.

My point is not that macro-level categories such as culture, ethnicity, and sect do not matter. They play a role in shaping the Buddhist healing repertoires at any given location in a general way. But, surely our analysis cannot end there. It is also critical to understand how any given institution is embedded within specific local contexts that contribute significantly to shaping its healing repertoires from the ground up. These meso- and micro-level factors present certain affordances that can be drawn upon by the community to support or facilitate engagement in healing and health-seeking in certain ways, and they also represent inhibitors or challenges for doing so. How each community-and indeed, each individual—responds to and navigates these ecosystems of opportunities and obstacles is highly individualized and unpredictable, and this in turn leads to unique configurations of healing and health-seeking in each instance.

The local context of individual Buddhist temples includes a whole range of social, economic, and idiosyncratic factors that call for analysis. Here, in the interests of space, I will only be able to point out a few salient examples as an illustration of the broader point.

\subsection{Socioeconomic Status}

In our research, we have observed that the socioeconomic status of the community an institution serves exerts a strong influence on the kinds of health-related activities in which it becomes involved. We have noted that temples serving socioeconomically disadvantaged populations tend to play more active roles in promoting health on a day-to-day basis. Responding to the immediate needs of their members, they may periodically host health fairs, serve as meeting-points for the exchange of traditional medicine treatments, or help members to connect with mainstream healthcare services by offering transportation or translation services. The Healthy Monks Project at Wat Phouthathammram, already mentioned above, is an example of one such community initiative. Similar initiatives take place on a fairly regular basis among certain temples in Center City.

Institutions with more socioeconomically affluent members, on the other hand, often are less connected with day-to-day healthcare needs, though they still may organize periodic religious festivals or cultural events that include a connection with healing. If these latter types of institutions are regularly involved with community healthcare, they are more likely to be doing so on a charitable or volunteer basis. That is to say, rather than organizing health fairs for their own members, these institutions are more likely to be involved in providing those services to other populations. The Won Community Services Center, the charitable outreach organization that is run out of the basement of the Won Buddhist Temple, is one such example, as are the veterans' clinics run by its affiliate, the Won Institute. 


\subsection{Neighborhood Demographics}

A second factor that can help shape the Buddhist healing offerings at any given institution is the racial demographics of the immediate neighborhood in which it is located. As noted above, most of the institutions we surveyed were located within neighborhoods with higher than average percentages of their target demographic. When the demographics of particular neighborhoods change over time, temples often move to follow their communities to new locations. However, demographic shifts can also inspire organizations to change which populations they serve. When the Won Community Services Center was created, for example, the primary demographic it served was incoming Asian immigrants. As the immigration patterns in the locale have shifted over the past decades, however, they now also find themselves providing health-related services to people from Africa, Latin America, Eastern Europe, and other parts of the world.

Meanwhile, Buddhist temples that are located in neighborhoods with a Caucasian majority often engage in outreach to the local neighborhood via cultural events, open houses, or weekly meditation classes taught in English. Some temples develop "parallel congregations": Two different racial, ethnic, cultural, or linguistic groups that meet separately under one roof. In our experience, it is typical for such organizations to provide markedly different experiences for each group, with the messaging and framing of the health benefits of Buddhist practice diverging widely to cater to culturally-specific interests and expectations (see below). ${ }^{37}$

\subsection{Institutional Networks}

Yet another factor that calls for analysis is the networks with which individual temples are connected. As already mentioned above, some of Philadelphia's Buddhist institutions are independent entities, some are affiliated with national or international associations, and some are offshoots or branches of temples in the home country or elsewhere in the US (most often, New York City). Some institutions are regional hubs attracting members from across the Greater Philadelphia area, while others are largely limited to specific neighborhoods. The size, shape, and nature of a given institution's networks frequently have a direct bearing on its health-seeking approaches and its capacity to organize or support health-related activities.

The degree to which the network is centralized is important in determining to what extent organizations can innovate or explore new healing activities. Guanyin Citta Dharma Door is an example of a highly centralized organization. The most direct means of healing for members of this far-flung international network is to communicate directly with the founder of that tradition, Lu Junhong, a Chinese-Malaysian living in Australia. By channeling the deity Guanyin (which other members cannot do) Master Lu remotely provides diagnoses of any ailments and prescribes the specific number of tally cards that can be used to acquire a cure. This direct reliance on a single charismatic leader ensures the organization maintains a tightly centralized and hierarchical network that revolves around frequent contact with the institution's headquarters and fosters dependence on a charismatic leader.

Connectivity with the home country in Asia may also be important in facilitating access to traditional medicines, herbs, information, and other resources. The Won Buddhist Temple and its affiliated organizations, for example, have close relationships with the Won Buddhist headquarters in Korea. These have translated into meaningful benefits for Won's mission in the US, including financial supports and a pipeline of clerics arriving in Philadelphia from Korea. The same connections have also enabled students and faculty from Won Institute's acupuncture program to visit Korea on several occasions. ${ }^{38}$ While in Korea, delegates of the Institute have interacted with the Won Buddhist flagship educational institution (Wongkwang University), several Won Buddhist hospitals, as well as the

37 The term "parallel congregations" was coined by Paul D. Numrich in (Numrich 1996).

38 The author shadowed a group of students on part of their visit in 2016 to observe and conduct interviews. 
Korean Institute for Oriental Medicine. According to one interviewee, these travels in Korea were in part meant to inspire the increase of Korean medicine (as opposed to Chinese medicine) in the school's curriculum.

The presence or absence of strong social media networks is also relevant. For example, members of the Philadelphia chapters of both SGI and Guanyin Citta participate in robust institutional social media outlets, including Facebook pages, WeChat groups, and so forth. ${ }^{39}$ These venues-which are avidly promoted to visitors-are filled with testimonials about the miraculous effects that chanting has had on their lives, often centering around matters of health. Such communications promote the organization at the international level, strengthen social connections between local chapters, and also serve to introduce and reinforce the message for participants and potential converts that Buddhism can have a tangible and transformative effect on one's health.

\subsection{Individual Medical Expertise}

Finally, a major influential factor on Buddhist healing activities is the presence within the community of members with professional expertise or experience in medical fields. Such individuals often are key players in creating, facilitating, or connecting with healthcare opportunities. At several temples, prominent lay leaders happen to be (or happen to have been in the past) nurses at hospitals either here in the Philadelphia area or back in the home country. Because of their expertise, these individuals are acknowledged by their communities as important resources and are sought out for advice. They frequently are tapped to oversee the health of the temples' monastics, giving them periodic check-ups, taking care of them when sick, and escorting them to the doctor or the hospital as warranted. ${ }^{40}$ As mentioned above, members connected to healthcare institutions are often responsible for organizing health fairs for the temple and the surrounding community. Of course, the presence of medical expertise in the community implies a certain socioeconomic standing and concomitant level of social capital. Temples where members are not so well-off or well-connected may not be able to organize such events.

\section{Four Case Studies from Greater Philadelphia}

Macro-level categories, such as ethnicity, culture, and sectarian affiliation, may possibly orient us to some larger trends or possibilities with regards to Buddhist institutions' involvements with healing. But their explanatory power is weak at best. More granular factors, such as members' socioeconomic status, neighborhood demographics, participation in networks, and the presence of individual expertise, result in unique configurations of opportunities and obstacles that strongly influence how Buddhist healing and health-seeking activities take shape in specific communities. Below, I present a series of four brief case studies that show how the configurations of such local factors have impacted specific institutions around the Philadelphia area.

These cases have been especially selected because they show the power of the local while nicely subverting overly simplistic top-down categorization schemes. The cases focus on a lone monk at a Korean Mahāyāna temple, a layman at a busy Vietnamese Mahāyāna temple, a Tibetan lama who leads a primarily Caucasian Tibetan meditation center, and the head minister of the Won Buddhist Temple. Each of these specific individuals have capitalized on the resources locally at hand in order to overcome particular shortcomings, or to pursue particular goals. In each case, the specific intervention has allowed the organization in question to expand its offerings of health-related activities and thereby become more relevant to its community-sometimes by bringing to the fore resources that previously existed within the cultural or doctrinal context of the institution, and sometimes by expanding the repertoires to supplement those resources from outside.

39 As part of our ethnographic research, we joined several of these social media groups.

40 See, e.g., interview with a Thai laywoman in chapter 35 of (Salguero forthcoming). 


\subsection{Cultivating Medicinal Herbs at Hwa Um Sa}

Hwa Um Sa (also known as Whaum Temple) is a Korean Mahāyāna temple established in 2001. The temple is affiliated with the Jogye Order, the predominant network of Mahāyāna temples in Korea. It is located in a residential home in Doylestown Township, about an hour north of Philadelphia. This locale, in an affluent and predominantly white part of Bucks County, has a very small local Korean population, and the temple is thus quite isolated from potential supporters. The single resident monk who lives at the temple speaks limited English despite being in the country for several decades (which is no doubt both a symptom and a cause of the lack of interaction between the temple and the surrounding primarily Caucasian neighborhood). The temple does not appear to offer any regularly scheduled religious services, and consequently does little to speak to the healthcare needs of the local population.

However, the temple does have a key resource that enables the resident monk to occupy a unique niche in the Buddhist healing landscape. Although there are at least three other Korean temples in the Greater Philadelphia area, two of which are also affiliated with Jogye, this particular building sits on a much larger plot of land than the rest. In addition to a walking meditation path that rambles through rock gardens, wooded areas, and fruit trees (Figure 4), the temple has enough acreage to accommodate a large vegetable and herb garden. Taking advantage of this resource, the resident monk imports from Korea the seeds of a number of medicinal plants-including wormwood, mulberry, and others-which he grows in large quantities in the temple gardens. Each year, he harvests this crop and dries the plants, which he subsequently distributes on the festival day of the Buddha's birthday to people who come to the temple from Philadelphia, as well as across Pennsylvania, New Jersey, Delaware, and New York City.

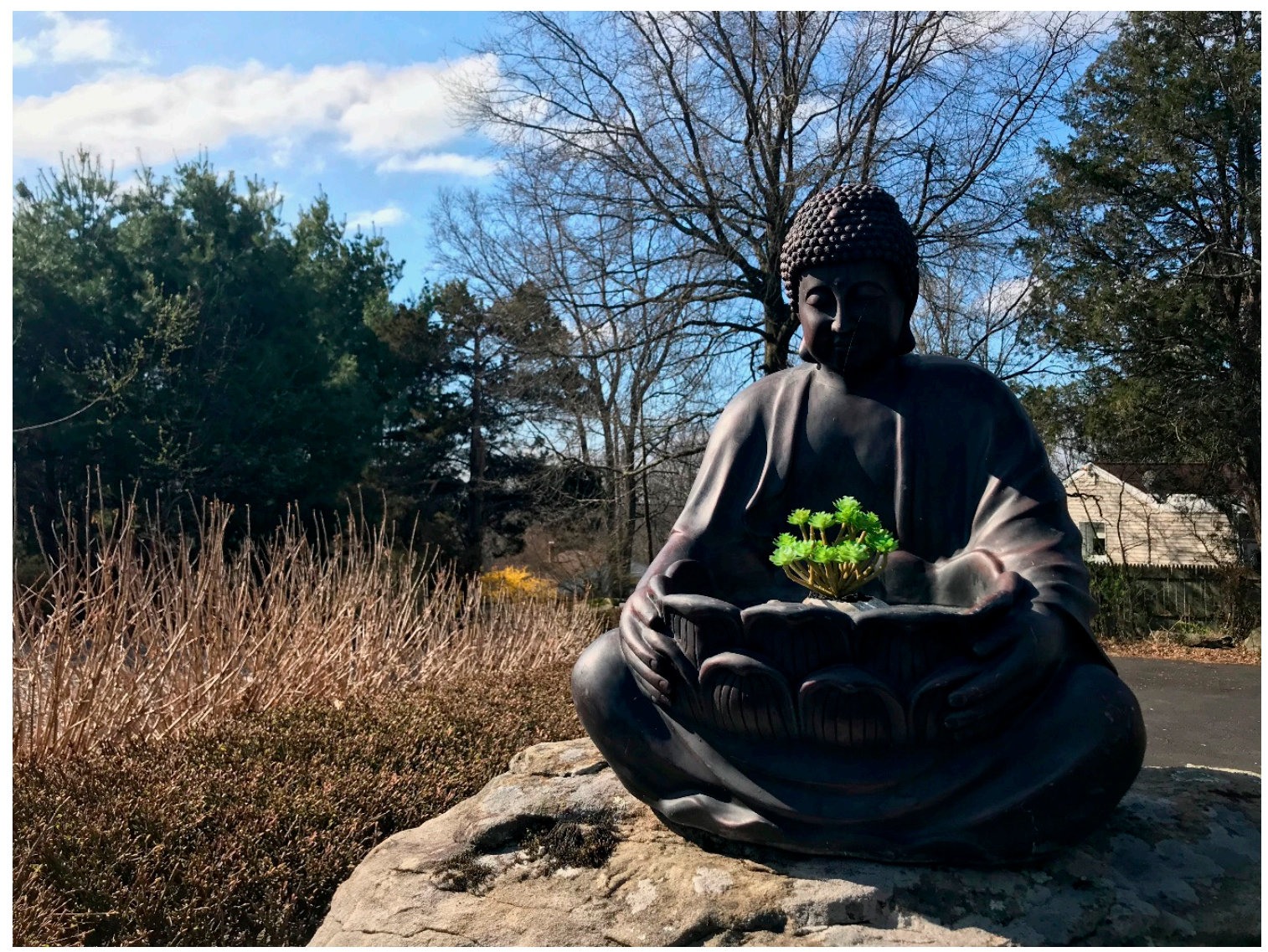

Figure 4. Buddha statue along the walking meditation path at Hwa Um Sa, (Doylestown, PA). Source: www.jivaka.net. 
During distribution times, the monk not only gives out herbs, but also provides instructions on how to prepare them, consults visitors on their ailments and reads their constitutions, and teaches about the herbs' potential benefits and contraindications. The monk denies that he is involved in medicine per se ("I'm not a doctor," he says). Rather, he sees himself as engaging in a more general way with certain aspects of Korean health culture, which values the knowledge of the health benefits of locally-grown herbs, plants, and foods. In this case, the temple's location in the exurbs presents a challenge, inhibiting the monk's connection with Korean supporters on a regular basis, but it also provides a unique affordance. A garden is not a specifically Korean or Mahāyāna resource. However, because he has enough space for a garden, this particular monk at this particular temple is able to overcome his geographic isolation and to become a repository of medicinal knowledge and plants for the dispersed Korean community across a wide area.

\subsection{Breaking from Tradition at Chùa Giác Lâm}

Named after a pagoda in Ho Chi Minh City, Chùa Giác Lâm is located just beyond the city line heading west, in Lansdowne, PA. This Vietnamese Mahāyāna temple attracts many young families with various activities and clubs for children. As is the case with all Mahāyāna temples, the main hall at Giác Lâm is the scene of many ceremonies of blessing and healing (Figure 5). The community's healing rituals are typical, revolving around chanting and prayer dedicated to Mahāyāna deities, such as Avalokiteśvara and Bhaiṣajyaguru.

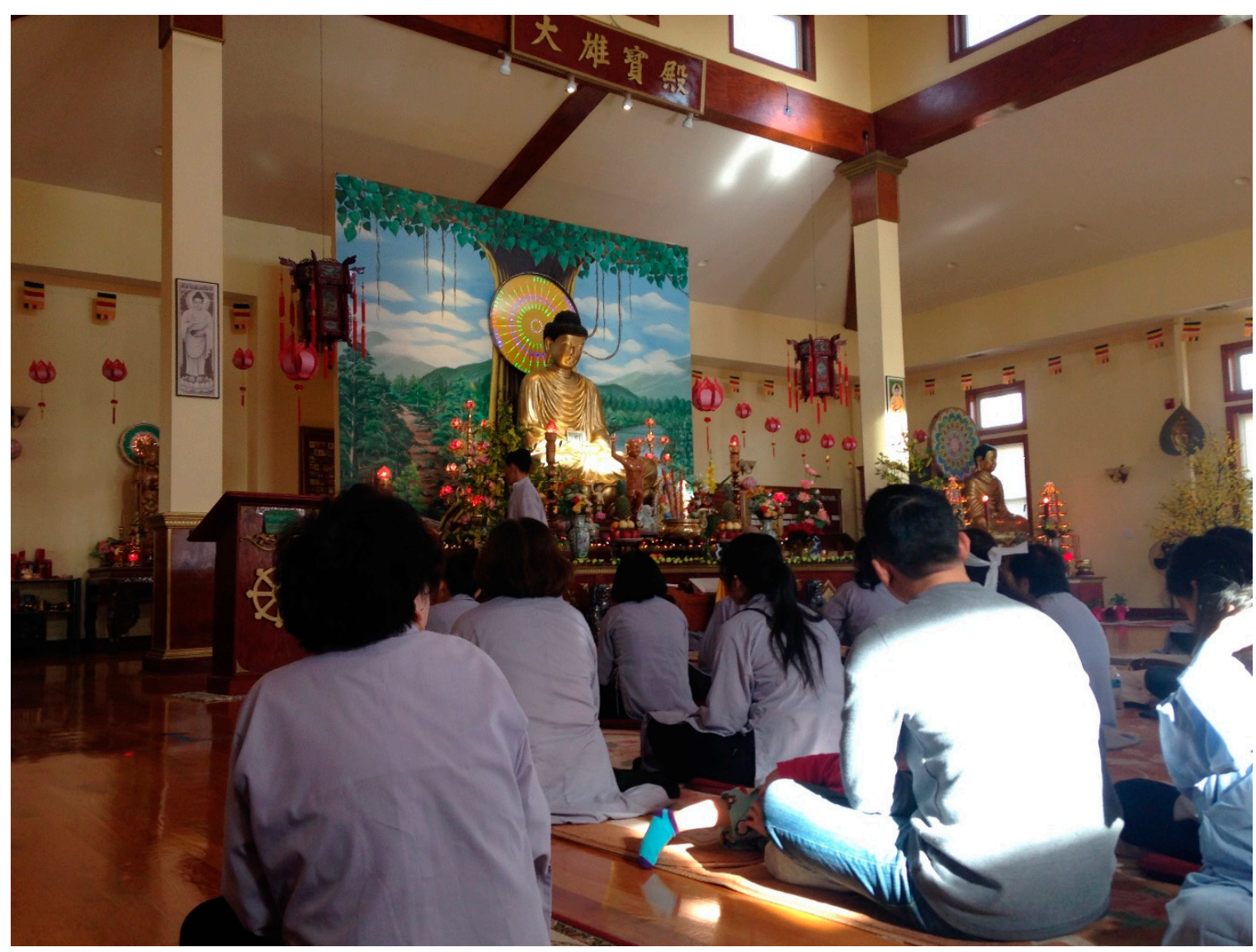

Figure 5. Main ceremonial hall at Chùa Giác Lâm (Lansdowne, PA). Source: www.jivaka.net.

What was not offered until recently at Giác Lâm was any form of formal meditation instruction. A few years ago, however, a lay member of the temple became dissatisfied with the lack of opportunities at the temple and started a weekly meditation group. Rather than seek out a Vietnamese-or even Mahāyāna-form of meditation, however, he decided to pursue a Theravāda style of meditation 
derived from Thailand. In our interview, the founder of the group reported that he made this choice because that particular variety of meditation has a reputation for powerful effects. He particularly mentioned that it slows down the physiological functions of the body, soothes stress, and can have a profound healing effect on the mind and body.

At the time of our interviews, the meditation group had been meeting on the grounds of the temple in a separate building immediately following the regular Sunday ceremony in the main hall and the communal vegetarian lunch. The participants in this group were all Vietnamese, most with only limited English ability. However, they were studying jhāna meditation, as taught by a prominent English-speaking Caucasian teacher. ${ }^{41}$ The founder of the group, who had been in the US longer and had greater facility with English, had been attending retreats and reading books by this teacher, and was now translating these teachings for his community.

At the time of our interview, the small meditation group remained somewhat marginalized within the temple institution. Its success was not a foregone conclusion. The establishment of the group required the willingness of the temple community-and its monastic leadership in particular-to sanction the group's meeting on the temple grounds. It was even more dependent on the initiative of a single member who was interested enough, persuasive enough, and who had enough language skills to cross doctrinal, ethnic, and linguistic boundaries in search of a "stronger" meditation. As a result of this particular configuration of factors, interested members of the community could now turn to jhāna meditation as one among the various types of healing or health-seeking activities that are offered on a weekly basis at Giác Lâm.

\subsection{The Charismatic Leader of Chenrezig Tibetan Buddhist Center}

Tibetan lama Losang Samten is the founder and spiritual head of the Chenrezig Tibetan Buddhist Center of Philadelphia and a renowned Tibetan sand mandala artist. First invited to the US in 1988, Losang has presented his mandalas at the Met, the Smithsonian, and in Martin Scorsese's film Kundun. Over the years, he has also been one of the few Asian-born Buddhist leaders that have been able to gain enough cultural capital to interface successfully with elite organizations in Greater Philadelphia. He now performs many multi-day sand mandala rituals around the area, including at museums, colleges, art galleries, churches, synagogues, and other cultural institutions.

One of the standard mandalas that Losang routinely constructs for his audiences is dedicated to the "Medicine Buddha" Bhaisajyaguru. According to Losang, he does not make these mandalas as part of the performance of a formal tantric Buddhist healing ritual, but merely as a way of sharing and educating about traditional Tibetan forms of sacred art. Nevertheless, as part of these events, he typically is invited to give a talk or to participate in a question and answer session about the mandala ritual, about Bhaiṣajyaguru, and about Buddhist concepts of healing more generally.

Losang's high public profile and connections with elite cultural institutions have meant that his meditation center has become well attended by an educated, well-off, primarily Caucasian segment of the population. (Among other techniques, they come to study the healing Green Tārā meditation mentioned above.) The demographics of his center stand in marked contrast to Philadelphia's oldest Tibetan Buddhist institution, the Temple of Saint Zonkava. Established in the 1960s by refugees from Kalmykia and Russia, this institution primarily serves members of Kalmyk, Mongolian, and Tibetan heritage. Although the temple was covered in the English-language press when it was visited by the current Dalai Lama in 2008, it has never become a popular destination for a wider swathe of Philadelphians. Meanwhile, Losang has become arguably the most high-profile Buddhist figure in Philadelphia, and something of a celebrity on the local Buddhist scene. His prolific activities around the area has meant that many Buddhists and non-Buddhists alike in Greater Philadelphia have been exposed to Buddhist ideas about healing directly (and, often, exclusively) though him. The key factors

41 On the various interpretations and roles of jhāna in American Buddhism, see (Quli 2008). 
here are neither ethnic, cultural, nor sectarian, but rather the coincidences of one individual's artistic skill, personal biography, and charismatic personality.

\subsection{Cultural Signals for Won Buddhist Temple's Parallel Congregations}

The Won Buddhist Temple is located north of the city in the suburban town of Glenside. This is the most significant Won Buddhist branch temple in the US, with a multi-building footprint that includes a temple, a residence hall for clergy, and a graduate school. A non-profit community services center is operated out of the temple basement.

In addition to the typical Won Buddhist service given in Korean, the temple hosts a weekly service in English. The services offered to these two parallel congregations are quite different in terms of their content. The Korean-language services include chanting to the buddhas Amitābha and Dharmakāya, as well as sermons and hymns, with little if any meditation. On the other hand, the English-language services focus mainly on meditation (including both seated and moving meditation) as well as "dharma talks" focusing on how spiritual cultivation, moral development, and mental stability can improve one's happiness and overall wellbeing. Direct physical benefits from regulating the $q i$ using meditation are also frequent topics of conversation. Aside from the prevalence of meditation, other elements of the English-language services also depart from Korean liturgical norms. In the English services we observed during our fieldwork, the singing of hymns was omitted altogether, the Heart Sütra was recited in English, and a span of time was spent chanting the Tibetan mantra OM MAṆI PADME HŪM. We also learned that a Zen priest or practitioner from another local Caucasian meditation group (i.e., a non-Won institution) is occasionally invited to lead the English-language service.

Such divergences are fairly unsurprising in the case of parallel congregations. ${ }^{42}$ However, it was not only the content of the services that was different at the Won temple, but also the cultural signals being sent. Like many Buddhist temples in Philadelphia, the Won Buddhist temple is located in a renovated church, and the building retains many of the features of its former life (Figure 6). The hybridity of the physical space is adeptly utilized as a resource in serving the needs of the temple's parallel congregations. During the Korean service, the Christian features are accentuated. Attendees sit on wooden pews that were inherited from the former church. Greeters, ushers, printed programs, and other accoutrements are employed in a similar way as they might be at any Protestant church. Though the service itself is punctuated with Korean-style bells, Buddhist woodenfish, and Korean-language chanting, at various points in the service the congregation stands to sing from printed hymnals, and these hymns have a notably Protestant musical style. In contrast, when English-language services are being offered, the pews are moved to the back of the hall and East Asian-style silk floor cushions are brought out. Attendees of these sessions sit cross-legged on the floor for the entirety of the service (except those portions of the moving meditation where the instructions ask participants to stand). Korean Buddhist implements and instruments (bells, woodenfish, etc.) are utilized liberally, and Protestant aesthetic elements are de-emphasized.

42 We observed a similar divergence between Wat Mongkoltepmunee's English-language classes, which focus exclusively on meditation, and their regular Thai services, which contain no meditation. 


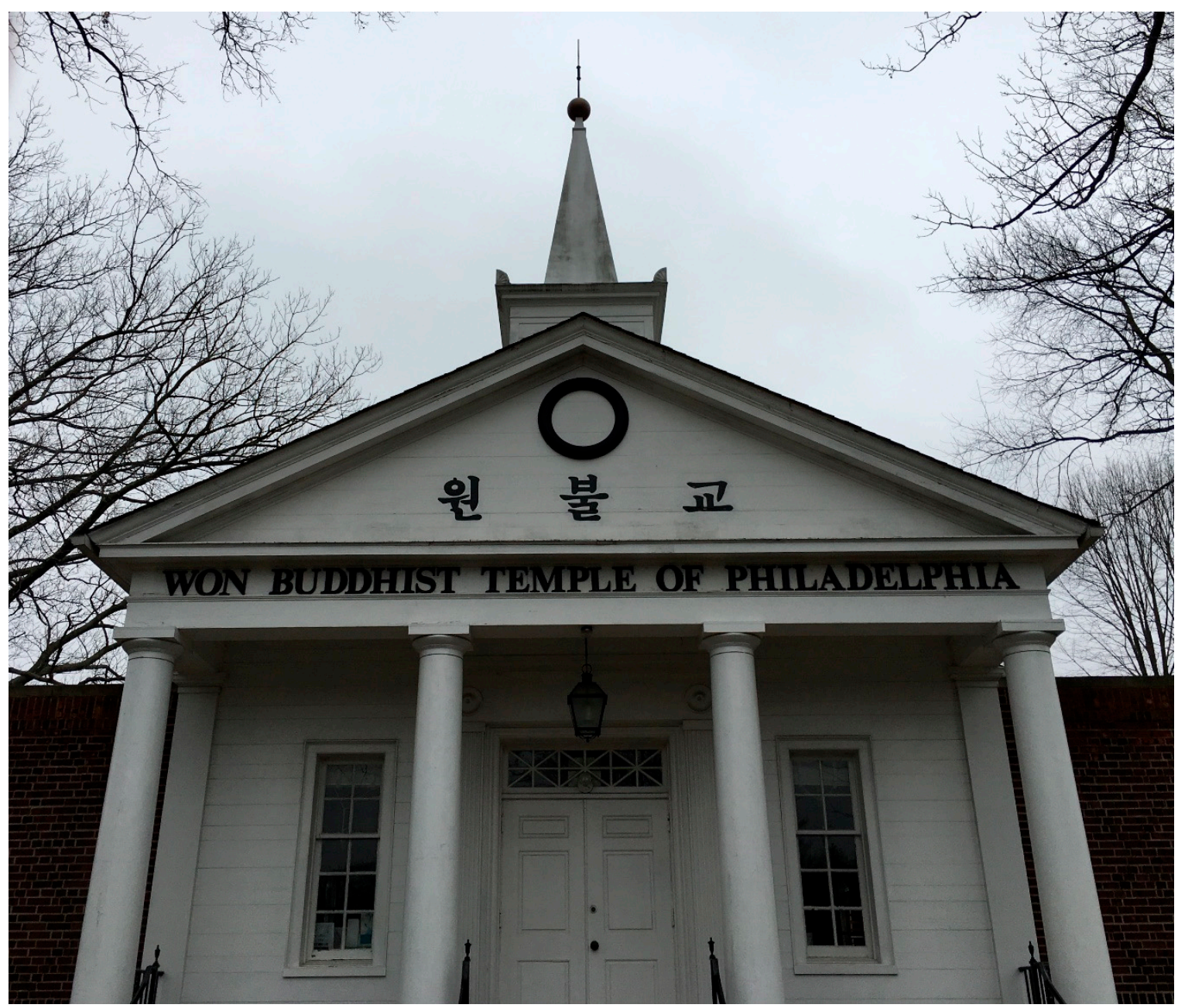

Figure 6. Won Buddhist temple (Glenside, PA). Source: www.jivaka.net.

As a non-traditional form of Buddhism originating in the early twentieth century, Won Buddhism has long modeled certain features of its habitus (e.g., priestly clothing, ritual activities, and music), as well as organizational structure after Christianity. ${ }^{43}$ These choices were no doubt advantageous in the context of twentieth century Korea, as Christianity was closely associated with progress and modernity and Won Buddhism wanted to present itself as a modern and reformed religion. These same cues have now become regular, expected parts of Won Buddhist culture for its Korean adherents, both in Korea and in the US. However, the head minister of Philadelphia's temple appears to have thought that these Christian influences were undesirable in the local context. Perhaps they were seen as potentially alienating non-Korean Philadelphians who attend Won services with stereotyped expectations of what Buddhist practice will look like. In any event, the minister chose to downplay the Christian influences and to emphasize the "Asianness" of Won Buddhism's meditation practice. ${ }^{44}$ These differences are not official Won Buddhist policy, but rather local strategic decisions about the use space, material culture, and aesthetics in order to send different cultural cues to different groups of local attendees.

43 See also (Chung 2002, pp. 4-5; Pye 2002, pp. 126-27; Baker 2012, p. 56). A comprehensive history of the founding of the order is given in (Chung 2002, pp. 3-109).

44 The minister in question has recently moved to a different temple in another city. In our interview, she reported that the aesthetic decisions described here were hers, but did not report her motivations. 


\section{Conclusions}

This paper has moved from a general discussion of Buddhism in Philadelphia, to a description of Buddhist healthcare repertoires, to an analysis of how local factors influence these practices in particular institutional contexts. Along the way, we have highlighted many different practices and orientations toward health and healing that are features of American Buddhism writ large. We have likewise mentioned in passing a spectrum of practitioners from monastic ritualists to organizers of health fairs, and from meditation teachers to hospital chaplains. We have critiqued previous scholarship that has too often overlooked the important ways that local factors make a difference in shaping Buddhist engagements in healthcare in specific communities. With the goal of moving past such broad characterizations and stereotypes, we have called for a more granular analysis, and have also provided a series of short case studies illustrating how the healing repertoires of four specific institutions have been influenced by unique configurations of local factors.

Our movement from the broad and general to the local and specific is intentional. At a time when American politics and national discourses are becoming increasingly fractured along ethnic, religious, cultural, and racial lines, it is more critical than ever to move beyond generalizations in order to gain greater understanding about the actual lived experience of diverse groups of Americans. In particular, the study of how immigrant and refugee communities access and utilize healthcare resources has become an urgent priority. Given the current reactionary changes taking place both national healthcare and immigration policies, it is imperative to measure, record, and understand how these communities are responding to the changing political landscape, and to the role of religious organizations as community resources.

Aside from a few minor articles that have focused narrowly on one particular temple or group of practitioners, scholars of Buddhism have published no large-scale studies of the role of Buddhist institutions in shaping health-seeking attitudes and behaviors in the US. Our study reveals that health is a major dimension of lived Buddhism at the local level. It also suggests that Buddhist institutions are particularly important points of entanglement between religion, healthcare, immigration, and intercultural exchange in marginalized communities. Further analysis of this data is of enormous and immediate relevance to healthcare policymaking-not to mention to our understanding of the contours of the social fabric in American urban centers. It is hoped that the project introduced here can be expanded to additional communities in the future, as we begin to build an understanding of the role of Buddhism in the multiethnic American healthcare landscape from the ground up.

Funding: This research was funded by various internal grants for pedagogical innovation at Penn State University.

Conflicts of Interest: The author declares no conflict of interest.

\section{References}

Amsterdam, Daniel, and Domenic Vitiello. 2013. Immigration (1930-Present). In The Encyclopedia of Greater Philadelphia. Edited by Charlene Mires and Randall Miller. Available online: https:// philadelphiaencyclopedia.org/archive/immigration-1930-present (accessed on 11 January 2019).

Baker, Don. 2012. Constructing Korea's Won Buddhism as a New Religion: Self-differentiation and Inter-religious Dialogue. International Journal for the Study of New Religions 3: 47-70. [CrossRef]

Baumann, Martin. 2006. Protective Amulets and Awareness Techniques, or How to Make Sense of Buddhism in the West. In Westward Dharma: Buddhism Beyond Asia. Edited by Charles S. Prebish and Martin Baumnn. Berkeley: University of California Press.

Beiser, Morton, and Feng Hou. 2017. Predictors of Positive Mental Health among Refugees: Results from Canada's General Social Survey. Transcultural Psychiatry 54: 675-95. [CrossRef] [PubMed]

Birnbaum, Raoul. 1989. The Healing Buddha. Boulder: Shambhala.

Braun, Erik. 2013. The Birth of Insight: Meditation, Modern Buddhism, and the Burmese Monk Ledi Sayadaw. Chicago: University of Chicago Press. 
Cadge, Wendy. 2004. Heartwood: The First Generation of Theravada Buddhism in America. Chicago: University of Chicago Press.

Chan, Sucheng. 1991. Asian Americans: An Interpretive History. Boston: Twayne.

Cheah, Joseph. 2011. Race and Religion in American Buddhism: White Supremacy and Immigrant Adaptation. New York: Oxford University Press.

Chung, Bongkil. 2002. The Scriptures of Won Buddhism: A Translation of Wonbulgyo Kyojon with Introduction. Honolulu: University of Hawaii Press.

Hickey, Wakoh S. 2010. Two Buddhisms, Three Buddhisms, and Racism. Journal of Global Buddhism 11: 1-25.

Hsu, Funie. 2016. What Is the Sound of One Invisible Hand Clapping? Neoliberalism, the Invisibility of Asian and Asian American Buddhists, and Secular Mindfulness in Education. In Handbook of Mindfulness: Culture, Context, and Social Engagement. Edited by Ronald E. Purser, David Forbes and Adam Burke. Cham: Springer.

McMahan, David, and Erik Braun. 2017. Meditation, Buddhism, and Science. Oxford: Oxford University Press.

Numrich, Paul. D. 1996. Old Wisdom in the New World: Americanization in Two Immigrant Theravada Buddhist Temples. Knoxville: University of Tennessee Press.

Numrich, Paul. D. 2005. Complementary and Alternative Medicine in America's "Two Buddhisms". In Religion and Healing in America. Edited by Linda L. Barnes and Susan S. Sered. Oxford and New York: Oxford University Press.

O’Neill, Mark. 2010. Tzu Chi: Serving with Compassion. Singapore: Wiley.

Ong, Aihwa. 2003. Buddha is Hiding: Refugees, Citizenship, the New America. Berkeley: University of California Press.

Pew Research Center. 2018. Philadelphia's Immigrants: Who They Are and How They Are Changing the City. Available online: https:/ / www.pewtrusts.org/en/research-and-analysis/reports/2018/06/07/ philadelphias-immigrants (accessed on 11 January 2019).

Purser, Ronald E., David Forbes, and Adam Burke, eds. 2016. Handbook of Mindfulness: Culture, Context, and Social Engagement. Cham: Springer.

Pye, Michael. 2002. Won Buddhism as a Korean New Religion. Numen 49: 113-41. [CrossRef]

Quli, Natalie. F. 2008. Multiple Buddhist Modernisms: Jhana in Convert Theravada. Pacific World 10: $225-49$.

Quli, Natalie. F. 2009. Western Self, Asian Other: Modernity, Authenticity, and Nostalgia for "Tradition" in Buddhist Studies. Journal of Buddhist Ethics 16. Available online: http:/ / blogs.dickinson.edu/buddhistethics / files/2010/05/quli-article.pdf (accessed on 11 January 2019).

Salguero, C. Pierce. 2017. Buddhism \& Medicine: An Anthology of Premodern Sources. New York: Columbia University Press.

Salguero, C. Pierce. Forthcoming. Buddhism \& Medicine: An Anthology of Modern and Contemporary Sources. New York: Columbia University Press.

Scott, Maiken. 2015. Nearly Killed by Kindness: Donated Food Hurt Monks' Health. Available online: https:/ / whyy.org/segments/nearly-killed-by-kindness-donated-food-hurt-monks-health (accessed on 11 January 2019).

Takaki, Ronald. 1989. A History of Asian Americans: Strangers from a Different Shore. Boston: Little, Brown.

Williams, Duncan Ryūken. 2019. American Sutra: A Story of Faith and Freedom in the Second World War. Cambridge: Harvard University Press.

Wilson, Jeff. 2008. “Deeply Female and Universally Human": The Rise of Kuan-yin Worship in America. Journal of Contemporary Religion 23: 285-306. [CrossRef]

Wilson, Jeff. 2014. Mindful America: The Mutual Transformation of Buddhist Meditation and American Culture. New York: Oxford University Press.

Wu, Hongyu. 2002. Buddhism, Health, and Healing in a Chinese Community. Available online: http://pluralism. org/wp-content/uploads/2015/08/Wu.pdf (accessed on 11 January 2019).

Yao, Yu-Shuang. 2012. Taiwan's Tzu Chi as Engaged Buddhism: Origins, Organization, Appeal and Social Impact. Leiden: Brill.

Yü, Chün-fang. 2001. Kuan-yin: The Chinese Transformation of Avalokiteśvara. New York: Columbia University Press.

(C) 2019 by the author. Licensee MDPI, Basel, Switzerland. This article is an open access article distributed under the terms and conditions of the Creative Commons Attribution (CC BY) license (http:/ / creativecommons.org/licenses/by/4.0/). 